Resgatando as Construções Geométricas com Instrumentos: Uma Experiência Vivenciada na Licenciatura em Matemática

\title{
RESGATANDO AS CONSTRUÇÕES GEOMÉTRICAS COM INSTRUMENTOS: UMA EXPERIÊNCIA VIVENCIADA NA LICENCIATURA EM MATEMÁTICA
}

\author{
Cristiane Borges Angelo ${ }^{1}$ \\ Universidade Federal da Paraíba
}

Ana Lúcia Nunes da Silva ${ }^{2}$

Secretaria de Educação do Estado da Paraíba

\begin{abstract}
Resumo
Este artigo objetiva apresentar uma experiência vivenciada em um mini-curso ministrado na IV Semana de Matemática, do Curso de Licenciatura em Matemática, do Campus IV - Rio Tinto, da Universidade Federal da Paraíba. O mini-curso teve como objetivos resgatar as construções geométricas utilizando instrumentos como régua, compasso e esquadros, familiarizar o participante com a régua, o compasso e o par de esquadros; e apresentar as propriedades de algumas figuras geométricas, por meio de construções com os instrumentos. Os conteúdos trabalhados foram retas paralelas, retas perpendiculares, ângulos e congruência de figuras, vinculados ao Bloco de Conteúdos "Espaço e Forma", dos Parâmetros Curriculares Nacionais de Matemática para o Ensino Fundamental - PCN. Baseamo-nos na obra "Programa de Desenho para a terceira e quarta séries ginasiais", de Benjamim de A. Carvalho, publicação datada de 1958, como fonte de referência para a elaboração e adaptação das atividades apresentadas nas atividades desenvolvidas no mini-curso. Confirmamos nossa hipótese inicial de que os instrumentos não são utilizados em aulas na Educação Básica. A proposta da utilização de instrumentos para o resgate das propriedades geométricas foi considerada válida, pois, para os participantes, auxilia na compreensão dos conteúdos relacionados à Geometria. Nesse sentido, a obra de Carvalho (1953) nos auxiliou na elaboração das sequencias didáticas, visto que os assuntos abordados no referido livro estão diretamente relacionados ao objetivo de nosso trabalho. Além disso, reiteramos que as propriedades das figuras geométricas podem ser melhor abordadas com o uso dos instrumentos de construção, para que o aluno consiga compreendê-las e visualizá-las enquanto realiza as construções.
\end{abstract}

Palavras-chave: construções geométricas; instrumentos; propriedades de figuras planas.

\section{Abstract}

This article aims to present an experience that happened in a mini course ministered on the IV Week of Mathematics, of the Mathematics Teacher Degree Program, of the IV Campus - Rio Tinto, of the Federal University of Paraíba. The mini course had as

\footnotetext{
${ }^{1}$ Email: cristianeangelo@dce.ufpb.br

${ }^{2}$ Email: anitxanunes@gmail.com
} 
Resgatando as Construções Geométricas com Instrumentos: Uma Experiência Vivenciada na Licenciatura em Matemática

objectives to redeem geometric constructions using instruments such as the ruler, compass and brackets, to familiarize the participant with the ruler, the compass and the pair of brackets; and to present the properties of some geometric figures, by means of construction with the instruments. The contents worked with were parallel lines, perpendicular lines, angles and congruence of figures, linked to the Block of Contents "Space and Form", of the National Curricular Parameters of Mathematics for Elementary Education - PCN. We based ourselves on the work "Programa de Desenho para a terceira e quarta séries ginasiais", from Benjamim de A. Carvalho, with publication dated from 1958, as source of reference to the elaboration and adaptation of the activities presented on the activities developed in the mini course. We confirmed our initial hypothesis that the instruments are not utilized in classes on Basic Education. The proposal of utilization of instruments to the rescue of the geometric properties was considered valid, because, to the participants, it assists on the comprehension of the contents related to Geometry. In this sense, the work of Carvalho (1953) assisted us on the elaboration of the didactic sequences, seeing that the subjects addressed on referred book are directly related to the objective of our work. Besides, we reaffirm that the properties of the geometric figures can be best approached with the use of the instruments of construction, so that the student can comprehend and visualize them whilst realizes the constructions.

Key words: geometric constructions; instruments; properties of flat figures.

\section{Introdução}

Este artigo objetiva apresentar uma experiência vivenciada em um mini-curso ministrado na IV Semana de Matemática, do Curso de Licenciatura em Matemática, do Campus IV - Rio Tinto, da Universidade Federal da Paraíba. O mini-curso teve como objetivos resgatar as construções geométricas utilizando instrumentos como régua, compasso e esquadros; familiarizar o participante com a régua, o compasso e o par de esquadros; apresentar as propriedades de algumas figuras geométricas, por meio de construções com os instrumentos; e avaliar a experiência tendo como fio condutor a percepção dos participantes quanto às atividades apresentadas.

As atividades trabalhadas no mini-curso fazem parte da proposta apresentada no Trabalho Final do Curso de Especialização em Matemática para o Ensino Fundamental, ofertado pela Universidade Federal da Paraíba. O referido trabalho apresentou uma proposta de sequência didática que resgatou as construções geométricas utilizando instrumentos como régua, compasso e esquadros no estudo das propriedades de triângulos e quadriláteros (SILVA, 2015), 
Resgatando as Construções Geométricas com Instrumentos: Uma Experiência Vivenciada na Licenciatura em Matemática

Partimos do pressuposto de que instrumentos como régua, compasso e esquadros, quando utilizados para fazer construções geométricas, podem possibilitar a visualização das propriedades das figuras geométricas, proporcionando um melhor entendimento acerca das referidas propriedades.

Considerando que atualmente o Desenho Geométrico não se faz presente no rol de disciplinas da Educação Básica e, como consequiência, raros são os materiais didáticos que contemplam atividades envolvendo construções geométricas, recorremos ao Repositório de Conteúdo Digital da História da Educação Matemática ${ }^{3}$ para pesquisarmos materiais que apresentassem atividades envolvendo construções com instrumentos. Assim, encontramos na obra "Programa de Desenho para a terceira e quarta séries ginasiais", cuja autoria é de Benjamim de A. Carvalho e publicação datada de 1958, uma fonte de referência para a elaboração e adaptação das atividades apresentadas no mini-curso objeto deste texto.

Dividimos esse texto em cinco partes, além dessa introdução. Primeiramente, apresentamos a metodologia da pesquisa, de acordo com a abordagem e objetivos e o instrumento utilizado. Em seguida fizemos algumas considerações teóricas sobre os temas Geometria e Desenho Geométrico. Após, apresentamos as atividades trabalhadas no mini-curso e a avaliação feita pelos participantes acerca da proposta. Por fim, encerramos o texto, sem a pretensão de esgotar o tema, apresentando as impressões obtidas acerca do trabalho realizado, tendo como foco de análise as percepções dos participantes.

\section{A metodologia}

Optamos nessa pesquisa pela abordagem qualitativa, pois nos permitiu "[...] explicar em profundidade o significado e as características do resultado das informações obtidas através de entrevistas ou questões abertas, sem a mensuração quantitativa de características ou comportamento.” (OLIVEIRA, 2007, p. 59)

No que diz respeito aos objetivos, esta pesquisa foi classificada como exploratória que, segundo Gil (2002), tem como objetivo proporcionar maior familiaridade com um determinado problema ou questão. Nesse sentido, a pesquisa foi

\footnotetext{
${ }^{3}$ Esse repositório é vinculado ao Grupo de Pesquisa de História da Educação Matemática no Brasil GHEMAT e sediado "fisicamente" na Universidade Federal de Santa Catarina.
} 
Resgatando as Construções Geométricas com Instrumentos: Uma Experiência Vivenciada na Licenciatura em Matemática

realizada junto a sujeitos que tiveram uma experiência prática com o problema pesquisado.

A experiência foi realizada na IV Semana de Matemática, do Curso de Licenciatura em Matemática, do Campus IV - Rio Tinto, da Universidade Federal da Paraíba, realizada em outubro de 2015. O tema dessa semana foi "Matemática: a linguagem da Ciência para a vida" e teve como público alvo alunos da licenciatura do referido curso. O mini-curso teve duração de duas horas e, ao longo desse período, foram apresentadas e trabalhadas cinco atividades envolvendo construções geométricas com instrumentos. Os sujeitos da pesquisa foram quinze licenciandos do Curso de Licenciatura em Matemática supracitado.

Nossa hipótese inicial era a de que os instrumentos régua, par de esquadors e compasso não eram utilizados em aulas na Educação Básica. Além disso, pretendíamos verificar se a proposta da utilização de instrumentos para o resgate das propriedades geométricas era considerada válida pelos participantes.

Utilizamos como instrumento de pesquisa um questionário composto por sete questões. As quatro primeiras questões eram objetivas e tinham três opções de resposta: sim; em parte; ou não. As demais questões eram subjetivas. Esse questionário foi aplicado aos participantes após a realização das cinco atividades propostas no minicurso. Nossa opção pelo questionário se deu em virtude de ser uma “[...] técnica para obtenção de informações sobre sentimentos, crenças, expectativas, situações vivenciadas [...] (OLIVEIRA, 2007, p. 83), o que atendia a natureza de nossa pesquisa.

\section{Considerações sobre a Geometria e o Desenho Geométrico}

A história da Geometria no Brasil nos mostra que os precursores desse campo de conhecimento em nosso país são os militares, pois na época do império, para desempenhar as funções militares, era necessário ser “[...] um matemático hábil, "expert" e astuto que conhece a arte da arquitetura militar, que faz reconhecimento das praças que se quer atacar que desenha trincheiras e galerias [...]" (VALENTE, 2007, p. 41, grifo do autor).

No início do século XX, em uma sociedade ainda agrícola, em que grande parte da população é analfabeta, o ensino de Matemática é voltado para as práticas cotidianas, 
Resgatando as Construções Geométricas com Instrumentos: Uma Experiência Vivenciada na Licenciatura em Matemática

em que "[...] busca-se o domínio das técnicas operatórias necessárias à vida prática e às atividades comerciais". (PAVANELLO, 1993, p. 2).

Com a criação das universidades de São Paulo em 1934 e no Rio de Janeiro em 1935, foram também criados os primeiros cursos para a formação do professor das diversas disciplinas do ensino secundário. Na mesma época, a organização advinda da reforma proposta para o ensino secundário, de Francisco Campos, divide esse nível de ensino em dois ciclos entre o fundamental e o complementar, institui programas referentes às distintas disciplinas e oferece instruções pedagógicas. Em relação ao ensino da Matemática, é perceptível a tentativa de unificar os vários ramos da Matemática, cabendo a um só professor a responsabilidade pela disciplina. (PAVANELLO, 1993).

Nas décadas de 1960 e 1970 com o advento do Movimento da Matemática Moderna (MMM) ocorre o abandono da Geometria nos programas escolares. Nesse período, os aspectos algébricos da Matemática foram bastante destacados.

Meneses (2007) sinaliza que esse movimento contribuiu para que professores de Matemática começassem a apresentar dificuldades nos conhecimentos geométricos. A esse respeito, o pesquisador afirma que:

\footnotetext{
esse abandono percebido principalmente durante os anos de 1960 a 1990 , também se refletia nos cursos de graduação de professores e nos cursos de magistério, pois esses cursos não tinham preocupação e nem um currículo voltado ao ensino da Geometria, fato esse que foi responsável pela geração de professores órfãos dessa formação e consequentemente sem a consciência da importância da aprendizagem desse conteúdo. Essa situação foi responsável pela formação de um grupo de professores que apresentava uma enorme dificuldade em abordar os conhecimentos geométricos deixando uma herança percebida ainda nos dias atuais. (MENESES, 2007, p. 04)
}

Podemos perceber, na reflexão supra mencionada, que a dificuldade dos professores de ensinar a Geometria ocorre por não terem a estudado em sua formação.

Com o advento da Lei de Diretrizes e Bases da Educação do $1^{\circ}$ e $2^{\circ}$ Graus - Lei 5692/71, há duas mudanças que corroboram para que o ensino de Geometria comece a entrar em decadência: a primeira que permite que cada professor escolha o que irá ensinar de acordo com a sua clientela e a segunda que acaba com o ensino de Desenho Geométrico (PAVANELLO, 1993). 
Resgatando as Construções Geométricas com Instrumentos: Uma Experiência Vivenciada na Licenciatura em Matemática

Com relação ao Desenho Geométrico a situação torna-se ainda mais preocupante. Essa disciplina permaneceu oficialmente por 40 anos consecutivos nos currículos escolares, de 1931 a 1971, mas deixa de ser obrigatória a partir da promulgação da LDB 5692/71. A esse respeito Zuin (2001) afirma que

\begin{abstract}
O Desenho Geométrico vai ter sua posição realmente abalada com a LDB $5692 / 71$, pois deixa de ser uma disciplina obrigatória, configurando apenas na parte diversificada do currículo. A parte diversificada incluía dezenas de opções. Sendo assim, podemos dizer que cada instituição escolar escolheu continuar ou não a trabalhar com esta disciplina na década de 70. Por que retirar das grades curriculares o Desenho Geométrico? Este passou a não ser mais um conhecimento socialmente válido e legítimo? Havia influência do Movimento da Matemática Moderna? [...] Neste ponto devemos lembrar que no Movimento da Matemática Moderna, a Geometria passou para um segundo plano nos currículos, sendo mesmo desconsiderada por alguns autores. Embora isto tenha ocorrido, o Desenho Geométrico manteve o seu lugar, pelo menos, em algumas escolas. (ZUIN, 2001, p. 106)
\end{abstract}

Consideramos que essa situação vem a contribuir para a situação atual deficitária em que se encontra o nível de conhecimento geométrico dos alunos, consequência do abandono do Desenho Geométrico e da própria Geometria nos currículos escolares. Apesar de atualmente termos orientações curriculares que enfatizam a importância do ensino da Geometria na Educação Básica, a exemplo dos Parâmetros Curriculares Nacionais (PCN) (BRASIL, 1998) que apresentam os conteúdos de Geometria em dois blocos: Grandezas e Medidas e Espaço e Forma, ainda percebemos uma dificuldade na inserção desses conteúdos nas salas de aula.

Os PCN orientam os professores a explorarem, em sala de aula, situações em que sejam necessárias construções geométricas com régua e compasso, a fim de que o aluno possa visualizar as propriedades de figuras. Além disso, os PCN afirmam que a utilização de instrumentos de medida possibilita aos alunos fazer conjecturas sobre as propriedades de figuras planas. (BRASIL, 1998).

Oliveira (2005) destaca quatro principais vantagens da utilização do Desenho Geométrico para a formação do aluno.

I. O Desenho permite concretizar os conhecimentos teóricos da Geometria, confirmando graficamente as propriedades das figuras geométricas.

II. Ao estudar as demais matérias, os alunos aprendem as linguagens verbal e simbólica. Ao estudar Desenho, aprende a linguagem gráfica, precisa e concisa, a mais antiga das linguagens. A 
Resgatando as Construções Geométricas com Instrumentos: Uma Experiência Vivenciada na Licenciatura em Matemática

criatividade técnico-científica, que é a capacidade de pesquisar e encontrar soluções consegue-se com uma teoria mínima, curta e inesquecível do Desenho. É como se estivéssemos desemaranhando um fio. Numa ponta do fio: o que se sabe. Na outra ponta: o que se quer.

III. Nada melhor que o desenho geométrico para resolver capacidades importantes como: organização, autodisciplina, iniciativa, serenidade e capricho.

IV. Com exercícios de Desenho apropriados para estimular a conexão de neurônios cerebrais, desenvolve-se a visão espacial. (OLIVEIRA, 2005, p.06)

A partir das vantagens apresentadas por Oliveira, podemos perceber o quanto o Desenho Geométrico se torna importante para a aprendizagem do aluno, fazendo-o elaborar conceitos em relação à Geometria a partir das construções geométricas.

Nessa direção, acreditamos que as construções geométricas podem contribuir para que o aluno desenvolva a sua percepção visual e espacial e consiga compreender de uma melhor forma as propriedades das figuras geométricas. Além disso, as construções geométricas possibilitam uma participação mais ativa do aluno em seu processo de aprendizagem.

\section{A proposta das atividades}

Pela síntese apresentada anteriormente, podemos observar que o Desenho Geométrico não está mais presente no rol de disciplinas da Educação Básica. Por esse motivo, existe uma grande dificuldade em encontrar materiais didáticos relacionados ao Desenho Geométrico. Nesse sentido, recorremos ao Repositório de Conteúdo Digital da História da Educação Matemática a fim de encontrar alguma obra antiga, da época em que o ensino de Desenho geométrico ainda era destaque na Escola Básica, em nosso país. Assim, encontramos o livro "Programa de Desenho para a terceira e quarta séries ginasiais", de Benjamim de A. Carvalho e nos baseamos nas atividades apresentadas nessa obra para elaborarmos as atividades que compuseram o mini-curso.

A obra "Programa de Desenho para a terceira e quarta séries ginasiais" é um livro que contém 203 páginas, divididas em duas partes: a primeira voltada para a terceira série ginasial e a segunda voltada para a quarta série ginasial. Em cada uma das partes, o autor faz a divisão em três capítulos, quais sejam: Desenho geométrico, Desenho Decorativo e Desenho Natural. 
Resgatando as Construções Geométricas com Instrumentos: Uma Experiência Vivenciada na Licenciatura em Matemática

O autor ainda apresenta dois programas oficiais de Desenho, um para a terceira série e outro para a quarta série. No livro há um destaque na parte de Desenho Geométrico para as construções geométricas usando os instrumentos régua, compasso e esquadros. Com essas construções são abordadas alguns conceitos relacionados à Geometria, tais como, perpendicularismo, paralelismo, ângulos, Triângulos e quadriláteros, dentre outros.

A primeira atividade elaborada para o mini-curso, intitulada "Conhecendo os instrumentos de medida" objetivou familiarizar os participantes com os instrumentos que seriam utilizados ao longo do mini-curso, a saber: régua, compasso e o par de esquadros. Para tal, solicitamos que os participantes formassem grupos na sala para que, em seguida, fizéssemos a distribuição dos instrumentos. Na sequência, solicitamos que os participantes manuseassem os instrumentos da maneira que eles acreditassem ser correto, para se familiarizar com o material. Após esse período de adaptação e reconhecimento do material fizemos os seguintes questionamentos aos grupos: 1) Vocês já conheciam esses instrumentos? 2) Já haviam utilizado algum deles em sala de aula? Qual (is)? 3) Vocês sabem como utilizar cada um desses instrumentos? Se sabem, expliquem para que serve e como devem ser utilizados? Após ouvirmos os participantes, partimos para a realização da segunda atividade.

A segunda atividade consistiu na construção de uma linha perpendicular a um segmento de reta $(\mathrm{AB})$, pelo seu ponto médio $(\mathrm{O})$. Para realizar essa atividade, os participantes utilizaram a régua e o compasso. Os conceitos envolvidos nessa construção foram segmento de reta, arcos de circunferência, reta perpendicular, distância entre dois pontos e ponto médio. Após a construção, solicitamos que os participantes respondessem as seguintes questões: 1) Que conclusão você chegou ao efetuar essas duas medições? 2) Se a abertura do compasso tivesse sido menor que a medida da metade de $A B$ iria ser possível construir a linha perpendicular? 3) E se a abertura do compasso tivesse sido diferente no traçados dos arcos, o que teria acontecido? Essas questões tinham como objetivo levar o participante a compreender que a reta perpendicular traçada passava pelo ponto médio do segmento, que a abertura do compasso adotada na construção iria influenciar no resultado e que, dependendo dessa abertura, a construção seria impossível, passaria pelo ponto médio ou passaria por um ponto qualquer do segmento. 
Resgatando as Construções Geométricas com Instrumentos: Uma Experiência Vivenciada na Licenciatura em Matemática

A terceira atividade proposta consistia em dividir um ângulo em duas partes de mesma medida, utilizando como instrumentos a régua e o compasso. Após a construção, os participantes deveriam responder a seguinte questão: 1) Como é chamada a semi-reta que você acabou de traçar? O objetivo desse questionamento era levar os participantes a reconhecer a semi-reta traçada como a bissetriz de um determinado ângulo.

A quarta atividade realizada consistiu na construção de um triângulo isósceles, conhecendo o ângulo oposto a sua base. Nos comandos dessa atividade estavam envolvidos conceitos como reta horizontal, reta perpendicular, circunferência e raio. Após a construção, lançamos as seguintes questões aos participantes: 1) Você observou que o triângulo construído possui dois lados congruentes? 2) Podemos afirmar que ele também possui ângulos congruentes? Para responder a questão 2, orientamos os participantes a utilizar o transferidor para verificar a medida dos ângulos do triângulo. $O$ objetivo dessa atividade era mostrar aos participantes a relação entre a congruência de lados e de ângulos em um triângulo.

A última atividade do mini-curso consistiu na construção de um quadrado conhecendo o seu lado. Os instrumentos utilizados foram o compasso, a régua e os esquadros. Após a construção do primeiro quadrado, solicitamos que os participantes traçassem as diagonais do quadrado e as medissem, utilizando a régua. Utilizando os mesmos procedimentos, solicitamos que fossem construídos outros dois quadrados e suas respectivas diagonais. Após, questionamos os participantes acerca de suas observações quanto às medidas das diagonais de um quadrado, no intuito de que eles percebessem que as diagonais de um quadrado têm as mesmas medidas.

Após a realização das cinco atividades acima apresentadas, propomos aos participantes que respondessem a um questionário, a fim de avaliarmos a experiência, tendo como fio condutor, para tal, a percepção dos participantes quanto às atividades apresentadas e ao tema abordado no mini-curso. A discussão desse instrumento será apresentada no item a seguir.

\section{A avaliação do mini-curso}


Resgatando as Construções Geométricas com Instrumentos: Uma Experiência Vivenciada na Licenciatura em Matemática

Conforme mencionado anteriormente, optamos pela utilização de um questionário, contendo sete questões, aplicado aos quinze participantes do mini-curso, após a realização de todas as atividades propostas.

A primeira questão solicitava que os participantes do mini-curso apontassem se a proposta das atividades havia contribuído para o seu aprimoramento acadêmico ou profissional. Quatorze participantes responderam que sim e um respondeu em parte. Nossa intenção ao fazer esse questionamento era verificar se os licenciandos em matemática consideravam importantes para a sua formação as atividades que exploravam as construções geométricas, propostas no mini-curso. A esse respeito, concordamos com Zuin (2001) ao afirmar que o estudo das construções geométricas propicia aos futuros professores um maior embasamento e compreensão de aspectos relacionados à Geometria Plana. Nesse sentido, ao observar que a avaliação nessa questão foi positiva, consideramos válida a inserção desse tipo de experiência no âmbito da formação de professores de Matemática.

A segunda questão pretendia saber se o mini-curso havia proporcionado uma nova experiência de aprendizagem. O objetivo dessa questão era verificar se as construções geométricas se faziam presentes no cotidiano dos licenciandos. Todos os participantes responderam sim a essa questão. De acordo com as respostas, pudemos observar que esse tipo de trabalho não era frequente na formação dos sujeitos da pesquisa, o que ratifica a afirmação de Zuin de que "o Desenho Geométrico foi sendo abolido das grades curriculares da grande maioria das escolas, principalmente nas escolas públicas” (ZUIN, 2001, p. 58). Vale ressaltar que não era nossa intenção verificar níveis de aprendizagem, mas perceber as atividades propostas já eram conhecidas pelos licenciandos.

A terceira questão dizia respeito ao mini-curso ter atingido as expectativas dos participantes. Como respostas a essa questão detectamos que quatorze participantes responderam que sim e um respondeu em parte. Sobre essa questão, vale comentar que, embora o instrumento de pesquisa utilizado no estudo tivesse sido o questionário de avaliação da experiência, fizemos algumas observações ao longo do mini-curso que nos permitiram perceber um grande envolvimento por parte de todos os participantes. Considerando que o título do mini-curso foi "Construções geométricas com instrumentos: uma proposta para o estudo das propriedades de figuras planas", 
Resgatando as Construções Geométricas com Instrumentos: Uma Experiência Vivenciada na Licenciatura em Matemática

concluímos, a partir das respostas dessa questão e da questão anterior, que os participantes conseguiram identificar algumas propriedades de figuras planas, a partir das construções geométricas, indo ao encontro das orientações dos PCN que orientam os professores de Matemática a desenvolver um trabalho em sala de aula que "explore situações em que sejam necessárias algumas construções geométricas com régua e compasso, como visualização e aplicação de propriedades das figuras, além da construção de outras relações" (BRASIL, 1998, p. 51).

A quarta questão perguntava aos participantes se já conheciam os instrumentos trabalhados nesse mini-curso. Dos quinze participantes, sete afirmaram que sim, seis afirmaram que em parte e um afirmou que não conhecia. As respostas obtidas nessa questão também sinalizam uma situação bastante preocupante, já que mais da metade dos participantes afirmaram conhecer em parte ou não conhecer os instrumentos.

A quinta questão solicitava que os participantes destacassem quais os pontos positivos no mini-curso. As respostas dadas a essa questão concentraram-se em duas categorias: a utilização de instrumentos para promover a aprendizagem, apontada por onze participantes; o uso de instrumentos para a construção de figuras geométricas, elencada por três participantes. Um participante não respondeu essa questão.

A sexta questão perguntava aos participantes se já haviam utilizado algum(s) do(s) instrumento(s) e em qual(is) situação(ções). Dois licenciandos afirmaram que nunca haviam utilizado; quatro afirmaram que tinham utilizado régua e transferidor; dois afirmaram que conheciam a régua e o compasso, três afirmaram que haviam utilizado somente a régua; dois participantes somente o transferidor; e dois transferidor e compasso. Observamos nas repostas que, dos quinze participantes, somente dois afirmaram que haviam utilizado algum dos instrumentos em aulas na Educação Básica. O restante dos participantes que sinalizou ter utilizado, afirmou que essa utilização aconteceu no Curso de Licenciatura. As respostas obtidas nessa questão vão ao encontro do chamado abandono da Geometria, evidenciado em nosso país a partir da década de 1970. Nesse sentido “a Geometria Plana e Espacial foi, ao longo das décadas, sofrendo cortes de vários tópicos no ensino fundamental e médio. O Desenho Geométrico foi sendo abolido das grades curriculares da grande maioria das escolas, principalmente nas escolas públicas.”. (ZUIN, 2010, p. 58). 
Resgatando as Construções Geométricas com Instrumentos: Uma Experiência Vivenciada na Licenciatura em Matemática

A sétima questão solicitava que os participantes se posicionassem quanto à proposta de utilização de instrumentos como régua, compasso, par de esquadros e transferidor no ensino de Geometria. Apenas um participante não respondeu essa questão. Os demais afirmaram que consideravam válida a utilização dos instrumentos, pois auxiliam na compreensão dos conteúdos relacionados à Geometria.

Nesse sentido, pudemos confirmar nossa hipótese inicial de que as construções geométricas podem possibilitar a visualização das propriedades das figuras geométricas, proporcionando um melhor entendimento acerca das propriedades das referidas figuras. Além disso, pudemos constatar que atividades de construções geométricas com a utilização de instrumentos como régua, compasso e par de esquadros não eram comuns na experiência vivenciada pelos participantes na Educação Básica.

\section{Considerações finais}

As considerações apresentadas ao longo desse texto tiveram como objetivo apresentar uma experiência vivenciada em um mini-curso, na qual resgatamos as construções geométricas utilizando instrumentos como régua, compasso e esquadros, no estudo das propriedades de triângulos e quadriláteros.

Após a finalização do mini-curso confirmamos nossa hipótese inicial de que instrumentos tais como: régua, compasso, esquadros e transferidor não são utilizados em aulas na Educação Básica. Além disso, a proposta da utilização de instrumentos para o resgate das propriedades geométricas foi considerada válida, pois, para os participantes, auxilia na compreensão dos conteúdos relacionados à Geometria.

Vale salientar que, nessa experiência, recorremos a uma obra antiga (CARVALHO, 1958) para elaborarmos as atividades desenvolvidas no mini-curso. Essa obra nos auxiliou na elaboração das atividades, visto que os assuntos abordados no referido livro estão diretamente relacionados ao objetivo de nosso trabalho. Nesse sentido, destacamos a importância de termos disponível em um repositório de conteúdos digitais obras que já saíram de circulação há bastante tempo, mas que podem subsidiar práticas a serem desenvolvidas em sala de aula na atualidade.

Por fim, ratificamos a importância desse tipo de experiência no âmbito da formação de professores de Matemática, pois propicia aos licenciandos o contato com 
Resgatando as Construções Geométricas com Instrumentos: Uma Experiência Vivenciada na Licenciatura em Matemática

os instrumentos, permitindo que os futuros professores conheçam novas possibilidades para o ensino da geometria, por meio de construções e visualizações de propriedades das figuras planas. Além disso, ratificamos que as propriedades das figuras geométricas podem ser melhor abordadas com o uso dos instrumentos de construção, para que o aluno consiga compreendê-las e visualizá-las enquanto realiza as construções geométricas.

\section{Referências}

BRASIL, Secretaria de Educação Fundamental. Parâmetros Curriculares Nacionais: Matemática. Brasília: MEC/SEF, 1998.

CARVALHO, Benjamin de A. Programa de Desenho: para a terceira e quarta série ginasiais. $6^{\mathrm{a}}$ edição. Companhia Editorial Nacional: São Paulo, 1958.

MENESES, Ricardo Soares. Uma história da geometria escolar: de disciplina a conteúdo de ensino. 2007. 172f. Dissertação (Mestrado em Educação Matemática). Pontifícia Universidade Católica de São Paulo, São Paulo, 2007.

OLIVEIRA, Clézio Lemes de. Importância do Desenho Geométrico. Disponível em: http://www.ucb.br/sites/100/103/TCC/12005/ClezioLemesdeOliveira.pdf. Acesso em: 07 de Julho de 2015.

OLIVEIRA, Maria Marli. Como fazer pesquisa qualitativa. Petrópolis, RJ: Editora Vozes, 2007.

PAVANELLO, Regina Maria. O abandono do ensino da geometria no Brasil: Causas e Consequências. Revista Zetetiké, Ano I - nº 1, 1993.

SILVA, Ana Lúcia Nunes da. Resgatando as construções geométricas com instrumentos: uma proposta para o estudo das propriedades de triângulos e quadriláteros. 2015. 55f. Trabalho de Conclusão de Curso (Especialização). Universidade Federal da Paraíba, João Pessoa, 2015.

VALENTE, Wagner Rodrigues. Uma história da Matemática no Brasil (1730 - 1930). $2^{a}$ edição. São Paulo: Annablume, 2007.

ZUIN, Elenice de Souza Lodron. Da régua e do compasso: as construções geométricas como um saber escolar no Brasil. 2001. 211f. Dissertação (Mestrado em Educação). Faculdade de Educação. Universidade Federal de Minas Gerais. Belo Horizonte, 2001. 